\title{
Silver phiale said to be from al-Juba (al-Wusța Governorate) — an archaeological puzzle
}

In March 2014, while recording finds in the Ministry of Heritage and Culture in alKhuwair, artefacts unexpectedly came to light reportedly from al-Juba in Oman's Bar al-Hikmān, in al-Wusța Governorate, until recently an archaeologically littleresearched part of the Sultanate. Some of the pieces could be attributed to the Samad LIA or perhaps the PIR, both from the centuries at the turning point of the ages from BCE to CE. Such finds have never before come to light in this part of Oman. Samad LIA sites are generally located some $220 \mathrm{~km}$ to the north on the southern flank of the al-Hajjar mountains in a zone c. $160 \mathrm{x} 105 \mathrm{~km}$ in area. Diagnostic pottery finds spread from Wadi Bānī Ruwāhah (UTM 40Q 620570 m E, 2561848 m N) eastwards to the coast, a smaller area than previously believed.

Keywords: al-Juba, Samad Late Iron Age, Période Préislamique Récente, Bar al-Hikmān, phiale, Oman XRF

\author{
Paul A. Yule ${ }^{1}$, Christine \\ Pariselle $^{2}$ \\ ${ }^{1}$ Sprachen und Kulturen des \\ Vorderen Orients — Semitistik, \\ Ruprecht-Karls-Universität \\ Heidelberg, Schulgasse 2, \\ D-69117, Heidelberg, Germany \\ ${ }^{2}$ Team Unit UMR 7041- \\ ArScAn, VEPMO (CNRS, \\ Université Paris X-Nanterre- \\ Université Paris 1) Archéologies \\ et Sciences de l'Antiquité-From \\ Village to State in the Near and \\ Middle East, Maison Archéologie \\ Ethnologie, 21 allée de \\ l'Université -Boîte 14, \\ F-92023, Nanterre Cedex, \\ France \\ e-mails: paul.yule@t-online.de, \\ parisellechristine@gmail.com
}

In March 2014, while recording finds in the Ministry of Heritage and Culture in al-Khuwair, artefacts unexpectedly came to light, reportedly from al-Juba in Oman's Bar al-Hikmān, in al-Wusța Governorate, until recently an archaeologically little-researched part of the Sultanate (Yule, 2002). Some of the pieces could be attributed to the Samad LIA (for an update on this cultural assemblage see Yule, 2016) or perhaps the PIR, both from the centuries at the turning point of the ages from BCE to $\mathrm{CE}$. Such finds have never before come to light in this part of Oman. Samad LIA sites are generally located some 220 $\mathrm{km}$ to the north on the southern flank of the al-Hajjar mountains in a zone c. $160 \mathrm{x} 105 \mathrm{~km}$ in area. Diagnostic pottery finds spread from Wadi Bān̄̄ Ruwāhah (UTM 40Q $620570 \mathrm{~m} \mathrm{E}, 2561848 \mathrm{~m} \mathrm{~N}$ ) eastwards to the coast, a smaller area than previously believed. Certain 'Samad' sites to the west (Bahla, BB04, Bawshar, Manah, Nizwa, Rustaq, Samā'il) show few or only marginally typical pottery finds in relation to the best-known sites. In 2001 the pottery was originally not the main criterion for the site attribution, and rather different criteria were used. The main sites lie east of the dotted line in the map in Figure 1.

Over the years a dealer (who shall remain nameless) has conducted unlicensed excavations that have yielded a striking so-called anthropomorphic figure fashioned of copper alloy (DA 24964: Yule, 2014a: 760, fig. 1a) of the third millennium BCE and the LIA finds mentioned above. The ministry takes a dim view of clandestine excavation and reports them to law enforcement, but it is occasionally obliged to acquire important artefacts before they are irrevocably lost. Yule took the trouble to speak first to the vendor on the phone and then to meet his accomplice in Mahawt, hoping for a more precise description of the find circumstances of the LIA finds. The dealer explained that some (inv. nos. DA 27062 to DA 27077) derived from a 


\section{P.A. YULE AND C. PARISELLE}

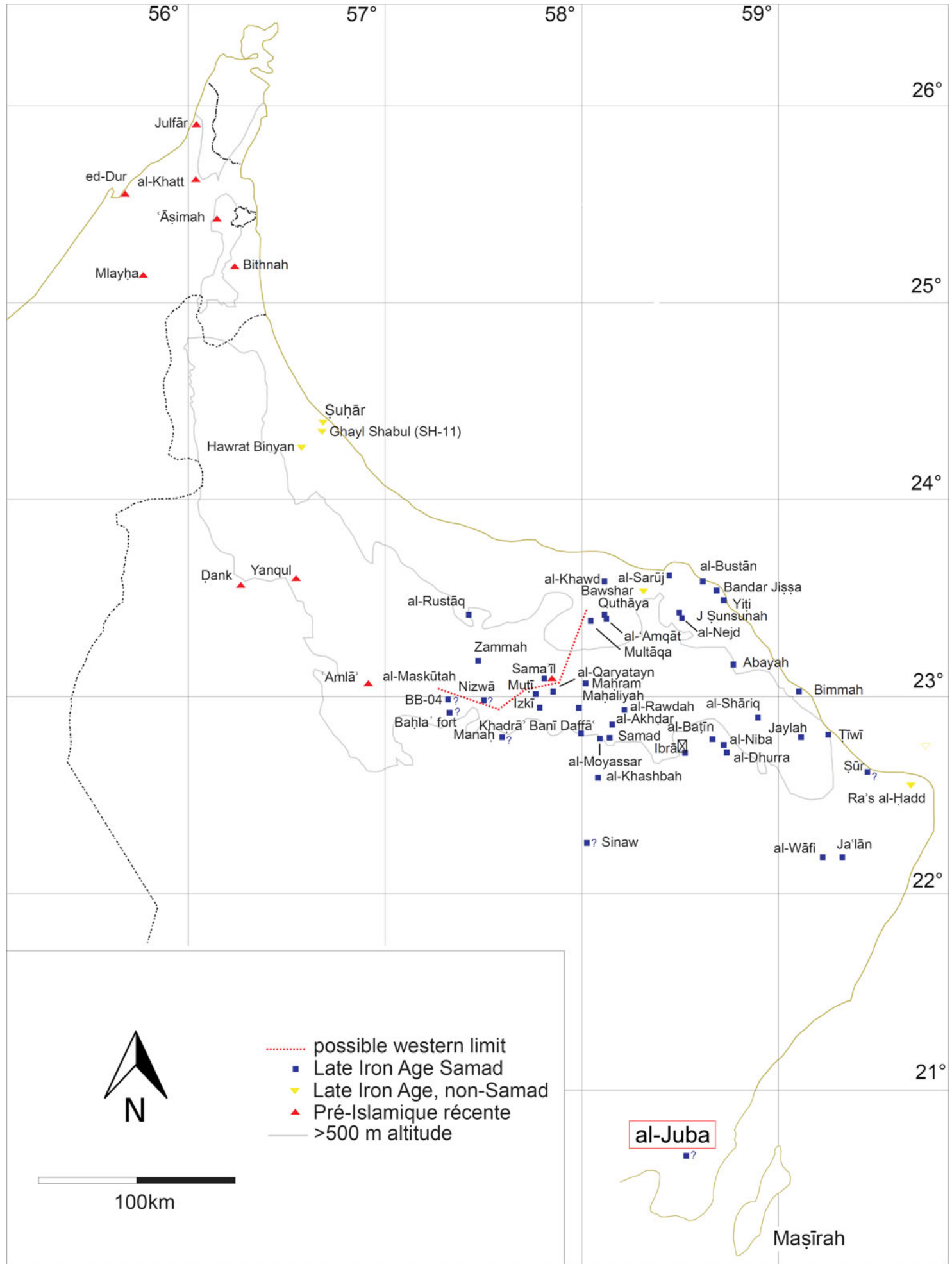

Fig. 1.

A map of south-east Arabia showing the sites mentioned (drawing: P. Yule). 
single grave, located in the prehistoric cemeteries which lie in the al-Juba flats, $20 \mathrm{~km}$ to the north of Mahawt town. Such a provenance for the finds, while interesting, cannot be verified, may be intentionally or unintentionally influenced and is certainly incomplete compared to that of scientifically excavated finds.

On 4 May 2015, a study group including Negar Abdali, Khalid al-Swafi, Mashal al-Shuaili and Paul Yule departed from the ministry in al-Khuwair to the al-Juba flats (300 $\mathrm{km}$ directly south as the crow flies) to inspect the cemetery areas which the ministry has mapped in the past two years (Fig. 1). That evening the dealer wordlessly presented a cardboard box which contained forty metallic vessel fragments 'from graves' for consignment to the ministry (see Figs. $6 \& 8$ ). The following day, after breakfast, the group returned to the flats in order to locate the grave, which allegedly yielded the Samad LIA finds. Isolated LIA graves are rare and it was hoped that others in al-Juba might be extant. Lacking these, during the LIA the area may have been uninhabited. In these vast burial areas, most of the numerous pre-Islamic graves are robbed, anciently, recently or both. They date perhaps to the third and second millennia, to judge from a few sherds scattered on the surface, and none resemble known LIA grave types (Yule, 2001a I: 27-45). Alas, the dealer's accomplice was unable to find the 'Samad grave' from memory, as it appeared to have been robbed down to the very last stone. The dealer explained that at first he had prospected with a metal detector but had not done so for several years. He was communicative and informed regarding the location of nearby ancient sites, showed us the cemetery and even the robbed grave near Sināw which yielded the abovementioned anthropomorph. We still had the fragmentary

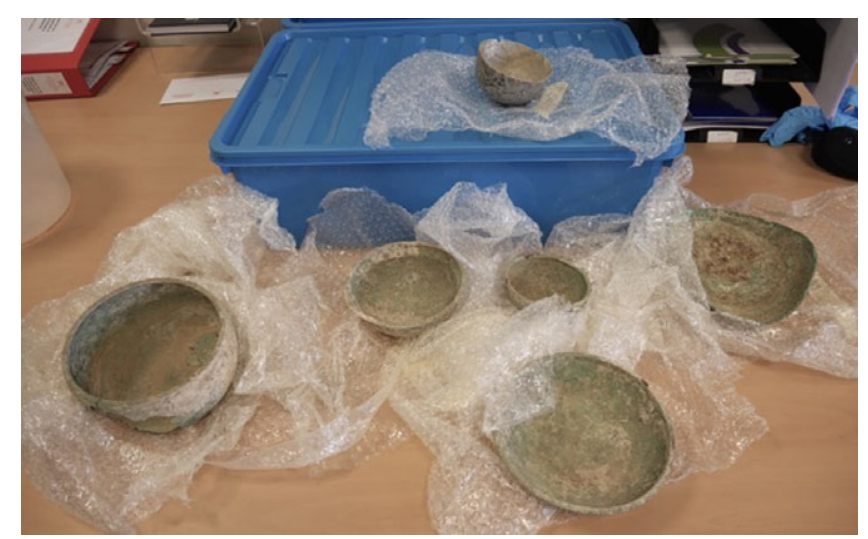

Fig. 2.

Metal vessels lodged in the ministry, said to be from al-Juba (photo: C. Pariselle). metal vessels from the dealer's clandestine activities and on arrival in al-Khuwair passed them on to the ministry.

The dilemma of the provenance situation is clear. Artefacts of a kind known from a part of central Oman and other exotic ones occur for the first time in the remote Bar al-Hikmān, but unfortunately with a dealer provenance that in final consequence cannot really be verified. This situation counters the training and ethics of the field archaeologist. Right from the start, 'suq archaeology' catapults him involuntarily into a class as a potential collaborator with antiquity dealers, as a possible one himself, as a silent witness to a crime, a helper's helper, etc. Other alleged al-Juba finds have occurred aside from those of this 'Samad grave'. A general overview of the metal vessels acquired from the dealer in 2014 appears in Table 1.

Our first examination suggested that the vessels could conceivably consist of a copper alloy. The oxidation varies from bowl to bowl. The phiale DA 27061 (Fig. 3/1), the bent pan DA 27063 (Fig. 3/3) and the bowls displayed in the same plate (except DA 27070) were in no way restored. Their surfaces showed a more or less thick layer of corrosion products covered with a discontinuous and extremely hard crust of sand including white mineral grains. If the dominant tonality of the corrosion layers was greenish, evocating copper corrosion products, punctually bulky blackish corrosion products were observed.

Our investigation started with the observation of the phiale DA 27062 (Figs. 3/2, 11-14) the surfaces of which was mechanically 'soft' cleaned (probably previously and also by us in April 2015) in order to make the decoration visible. The remaining thin and porous corrosion layer hiding the engraved patterns pointing out the original surface, showed a particular corrosion facies. Under a green veil of copper carbonates, the corrosion had mainly brownish and blackish colouration and showed small swollen crusts. Under this thin layer, mechanical tests allowed us to highlight a metallic shining grey surface. Moreover, the metal seemed almost totally mineralised (observed in the white section of a small fragment detached from the damaged edge).

Our hypothesis was that the phiale could be made of native silver containing impurities as copper, or could be base silver containing other metallic elements as copper (alloy) added in order to harden it (see below the metal analysis results).

Among the vessels corpus, two pieces particularly caught our eye: the anciently bent and untreated pan DA 27063 (Fig. 3/3) and the chemically over-cleaned bowl DA 27070 (Figs. 3/8, 5). In a section of a hole damaging 
P.A. YULE AND C. PARISELLE

Table 1. Selected metal vessels from 'al-Juba' stored in the Ministry of Heritage and Culture (cf. Figs. 2 \& 3).

\begin{tabular}{|c|c|c|c|c|c|c|c|c|c|}
\hline Shape & Material & Diameter $\mathrm{cm}$ & Decoration & Weight g & Condition & Shape class & Date & DA No. & Fig. No. \\
\hline phiale & $\mathrm{Ag}$ & 15.2 & $\begin{array}{l}\text { inside } \\
\text { and on outer rim }\end{array}$ & 252 & 'soft' cleaned & $\mathrm{MeOB} 12$ & LIA & 27062 & 3.2 \\
\hline pan & $\begin{array}{l}\mathrm{Cu} \text { alloy or } \mathrm{Ag} \\
\text { (optical ID) }\end{array}$ & 1722 & $\begin{array}{l}\text { possibly } \\
\text { not decorated }\end{array}$ & 289 & $\begin{array}{r}\text { surface corrosion, } \\
\text { laterally crushed }\end{array}$ & $\mathrm{MeP} 3$ & $?$ & 27063 & 3.3 \\
\hline bellied bowl, ledged rim & $\begin{array}{l}\text { Cu alloy or } \mathrm{Ag} \\
\text { (optical ID) }\end{array}$ & 16.8 & $\begin{array}{l}\text { possibly } \\
\text { decorated inside }\end{array}$ & 471 & interior corrosion & none & WS ? & 27065 & 3.4 \\
\hline bowl beaded rim & $\begin{array}{l}\mathrm{Cu} \text { alloy } \\
\text { (optical ID) }\end{array}$ & 12.2 & not decorated & 198 & $\begin{array}{l}\text { heavy surface } \\
\text { corrosion }\end{array}$ & MeGB03 & EIA & 27068 & 3.6 \\
\hline bowl, thickened rim & $\begin{array}{l}\mathrm{Cu} \text { alloy or } \mathrm{Ag} \\
\text { (optical ID) }\end{array}$ & 10.5 & $\begin{array}{l}\text { possibly } \\
\text { decorated } \\
\text { inside }\end{array}$ & 200 & heavy corrosion & near MeOB12 & LIA & 27069 & 3.7 \\
\hline bowl, gently tipped out rim & Ag (optical ID) & 9.910 .8 & plain & 40 & clean & none & $?$ & 27070 & 3.8 \\
\hline
\end{tabular}

the pan silver was clearly observed, while the white and dull metal composing the bowl could certainly be mineralised silver. Some of the objects (Figs. 3/1, 6 \& 7) were mantled with a thick oxidation layer.

Some of the vessel shapes briefly summarised in Table 1 are known, others not. Figure 3/6 is an EIA shape (MeGB3). Those of the MeOB12 class (Fig. 3/1-2) are dated to the LIA. Figure $3 / 4$, however, finds a vague match in a tomb with mixed finds, al-Buhais BHS2 in the UAE (Jasim, 2012: 32 fig. 30.3) which contains both Wadi Suq and EIA finds. Some of the metal vessels from this Buhais grave cannot be attributed compellingly to the EIA and might date rather to the Wadi Suq period, the vessel forms of which are less well known. Strikingly, several of the 'al-Juba' bowls were fashioned in silver, which until now has seldom survived (for an exception see Yule, 2014b: 114, pl. 2.3). For this reason and owing to the shape, some may actually have originated from the same context or a limited number of contexts. The dealer gave 'al-Juba' as the provenance for further finds.

Table 2 summarises key find attributes of the 'al-Juba' finds, although these are chronologically mixed and not plausibly from one grave. A few of the finds are attributable to the Samad LIA or PIR, especially the metal bowls of the shape class MeOB12, the pouring spout (Fig. 4/2), the soft-stone tumbler and its lid (Fig. 4/4) as well as the perfume bottle (Fig. 4/9). On the other hand, some pieces are unique, undifferentiated (Fig. 4/7-8), earlier (Fig. 4/6) or far earlier in date (Fig. 4/3-5). Figure 4/6 is an EIA arrowhead of the P8 class (Yule \& Weisgerber, 2015: 28, fig. 3). The mirror (Fig. 4/3) is most closely matched at Shahdad (later third millennium BCE) in Kerman
Province (Hakemi, 1997: 654 types Gv.1 \& Gv.2). Figure $4 / 5$ shows a broad and ribbed dagger of the D5.1 class best known from 'Āṣimah alignment As2 (Vogt, 1994: 119, fig. 54.6). While the previously mentioned tomb BHS2 contained Wadi Suq and EIA finds, the latter grave/ alignment is of Umm an-Nar date.

Striking are two metal handles bearing the provenance 'al-Juba', which originally derive from a Roman imported basin (Figs. 4/1, 7). During our visit to Mahawt, one of the corroded vessels given to us appeared to be the original that belonged to the two handles that were acquired a couple of years before. It was a basin, originally some 33 $\mathrm{cm}$ in diameter, of which some $50 \%$ of the vessel wall was extant. Jagged breaches in the vessel wall (Fig. 8) have remained where the handles were once attached. The dealer explained that the handles did not belong to the basin, which seems doubtful. This Roman form occurs at sites excavated in northern Germany, Denmark and Pomerania (Fig. 9), and also in South Asia (De Puma, 1991: 91-93, fig. 5.13 16). Over the centuries that they spend buried in the ground, however, the handles and stand-ring often become detached from the vessel wall. Figure 10 shows a reconstruction drawing of this Roman vessel type. Neither the dealer nor his accomplice tendered a stand-ring, nor was there any trace of one on the corroded vessel base. The two handles fit plausibly on the basin wall. Roman imports are common luxury goods at the sites of Mlayha and ed-Dur in the UAE (Haerinck, 2001), but are quite rare in Oman (Yule, 2016).

Unfortunately, we were unable to locate any graves from where the LIA 'al-Juba' finds might plausibly derive. Locating them will require a considerable investment in 

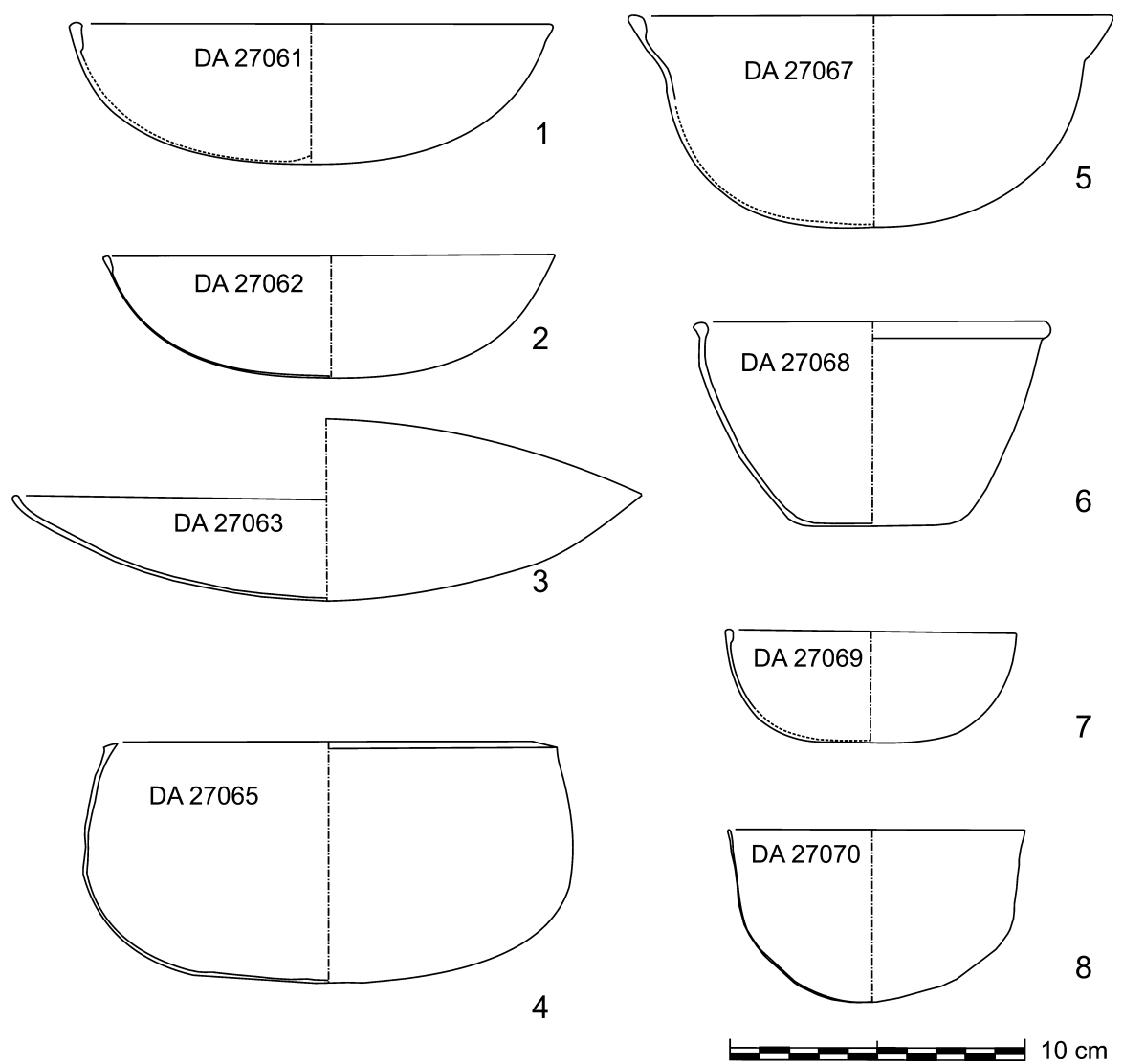

Fig. 3.

Profile images of the metal vessels in Table 1. No. 3 is anciently bent (drawing: P. Yule).

Table 2. Other artefacts from 'al-Juba' stored in the Ministry of Heritage and Culture, not listed in Table 1.

\begin{tabular}{|c|c|c|c|c|c|c|c|c|c|}
\hline Artefact & Material & Diameter Length & Decoration & Weight $g$ & Condition & Shape class & Date & DA No. & Fig. No. \\
\hline phiale & Ag (optical ID) & $16.3 \mathrm{~cm}$ & $\begin{array}{l}\text { engraved } \\
\text { inside }\end{array}$ & 368 & interior oxidised & $\mathrm{MeOB} 12$ & LIA & 27064 & - \\
\hline handle & $\mathrm{Cu}$ alloy & $14.7 \mathrm{~cm}$ & none & 224 & 'soft' cleaned & none & Roman, 1 st cent. CE & 27071 & 7 \\
\hline dagger & $\mathrm{Cu}$ alloy & $26 \mathrm{~cm}$ & none & 183 & lightly oxidised & D5.1 & Umm an-Nar-LBA & 27073 & $4: 5$ \\
\hline arrowhead & $\mathrm{Cu}$ alloy & $7.1 \mathrm{~cm}$ & none & 20 & corroded & P8 & EIA & 27074 & $4: 6$ \\
\hline arrowhead & $\mathrm{Cu}$ alloy & $6 \mathrm{~cm}$ & none & 9 & corroded & P3 & WS?, LIA & 27075 & - \\
\hline chisel & $\mathrm{Cu}$ alloy & $16.7 \mathrm{~cm}$ & none & 34 & corroded & Mei & WS & $27078 \mathrm{a}$ & $4: 7$ \\
\hline razor & $\mathrm{Cu}$ alloy & $8.3 \mathrm{~cm}$ & none & 34 & corroded & R04 & WS, LBA & 27080 & - \\
\hline vessel + lid & soft stone & $4.5 \mathrm{~cm}$ & $\begin{array}{l}\text { mult. horiz. } \\
\text { lines }\end{array}$ & - & excellent & $\operatorname{Sg} 36$ & LIA & 27083 & $4: 4$ \\
\hline small parts & $\mathrm{Cu}$ alloy & - & none & - & light oxidised & - & $?$ & 27084 & - \\
\hline perfume bottle & terra cotta, glazed? & $8 \mathrm{~cm}$ & gold glaze & - & oxidised, chipped & near G11.04 & LIA & 27089 & $4: 9$ \\
\hline
\end{tabular}

time, if in fact they exist(ed) at all. In all likelihood, LIA graves are extremely rare in this area since none have ever been reported despite considerable recent surveying (e.g. Rose et al., 2012).
Proving the originality of the 'al-Juba' vessels beyond all philosophical and legal doubt is a challenging though perhaps futile task. While hitherto in the Sultanate the faking of antiquities has been unimportant, in the Yemen it is 
an insidious malignant industry, which is clear from Yule's own observations over the years of confiscated examples in the antiquities service, GOAM, in Șan' $\bar{a}$ '. This dubious trade appears to be less widespread in the UAE, but numerous fake metal vessels from Iran are on sale there (Dan Potts, personal communication). But how can we uphold the originality of rare objects and how can doubters disprove it solely by virtue of a casual glance at a photograph? If we argue for the originality of these artefacts, we have to rely on the scant evidence from forensic post hoc visits to the alleged robbed sites, the composition of the find inventories as we know them, the peculiarities of the corrosion of the finds and their financial unimportance. In light of Yule's experience with metal vessels and the archaeology of Oman and elsewhere for over three decades (e.g. Yule, 2016), none of the artefacts under discussion awake suspicion. In the final analysis, one has to rely on one's own intuition that suspicion of a forgery is both clear and present, or is remote. Such judgements usually rely on comparisons with other artefacts, it is hoped from controlled excavation. If a given piece is unique, we are faced with another problem: excavations in Oman often yield unique artefacts. A few years ago, one Gulf specialist was shown a decorated bronze phiale from 'Amlā'/alFuwaydah; he questioned its authenticity until it was revealed that it had been excavated (Yule, 2016: fig. 6.1). One argument for the genuineness of the 'al-Juba' phiale is the peculiar manner in which the corrosion attacked the exposed engraving more than the vessel surface, which suggests a long period, even centuries, of oxidation (cf. Figs. 12 \& 13).

Perhaps the most interesting 'al-Juba' find is the complete engraved phiale, anciently torn in field 7 where a ring was once attached (Figs. 11-14), probably like the copper alloy ring from another metal vessel from Samā'il (Yule, 2001a I: 401; 2001a II: Taf. 534.4). At first, we could not clearly determine the bowl's metal. Although in less corroded spots it had a silvery sheen, this might have resulted from plating on some other metal. As previously mentioned, in the National Museum sand was removed from

Table 3. Clockwise sequence of motifs in phiale 2015.6140.

\begin{tabular}{|ll|}
\hline field 1 & rampant addorsed quadrupeds \\
field 2 & lion attacks bovid \\
field 3 & rampant addorsed caprids \\
field 4 & female figure grasps snakes \\
field 5 & rampant addorsed caprids \\
field 6 & lion attacks bovid \\
field 7 & rampant addorsed caprids \\
field 8 & female figure grasps quadrupeds \\
\hline
\end{tabular}

the surface, that is, only a 'soft' cleaning was applied. In order to get a first idea of the composition of the metal we turned to non-destructive X-ray fluorescence (XRF) measurements. To begin with, a $5 \times 3 \mathrm{~mm}$ surface on the base was freed of corrosion. We took a reading on the inside and outside of the vessel. The first metal analyses nos. 1a and $b$ were made at the Pfandhaus-KA in Karlsruhe, Germany. Figure 11 shows all of the points assayed.

Analyses 1a and 1b show the surface material to be silver, with some copper and trace elements, but the two analyses deviate from each other $(\mathrm{Ag} 92 \%$ and $\mathrm{Cu}$ $8 \%$ compared with $\mathrm{Ag} 73 \%$ and $\mathrm{Cu} 26 \%$ ). The differences may result from taking the respective readings at slightly different spots, that is, on non-oxidised and partially oxidised surfaces ('target effect'). Later, XRF measurement nos. 113 were taken at the Archäologische Staatssammlung in Munich. These were made with a Thermo Scientific Niton XL3 XRF analyser, which also photographs the sampling target making the aiming easier and thus the discussion more cogent. This instrument searches quantitatively for twenty-six elements, of which the four most important ones appear in Table 4.

Of the latter, only measurement 1 was made inside a measurement chamber. Nos. 1 to 9 were taken of the outside surface of the phiale. Nos. 10 to 12 were taken inside. Munich samples nos. 1 and 2 are on the same spot as Karlsruhe 1a and Munich 10 as Karlsruhe $1 \mathrm{~b}$ (see below in Fig. 11). The two sets of measurements verify each other. If one averages the silver content of the inside and outside (measurements 1-13) they are about the same, respectively $62.57 \%$ and $65.23 \% \mathrm{Ag}$. There is no reason to consider inside/outside enrichment or depletion. The situation within the vessel wall is a different issue.

Wide variations in the silver/copper content measured originate in three main ways. First, the vessel surface was cleaned to bare metal only in one spot on the outside, too small to always pinpoint perfectly with the XRF. Some of the measurements are partly of the oxidised surface. Second, the surface enrichment of archaeological silver-copper alloys has been recognised for many years (Beck et al., 2004: 153). Third, the original composition may have been somewhat heterogeneous. Other aging effects during the 2000-year burial are too complex to discuss in the framework of this short paper.

The interior decoration of the phiale is unique. Radially composed around a leafy central motif, double borders $c .6$ $\mathrm{mm}$ apart form eight trapezoidal panels. The radiograph (Fig. 12) was taken of the outside surface; thus, the 

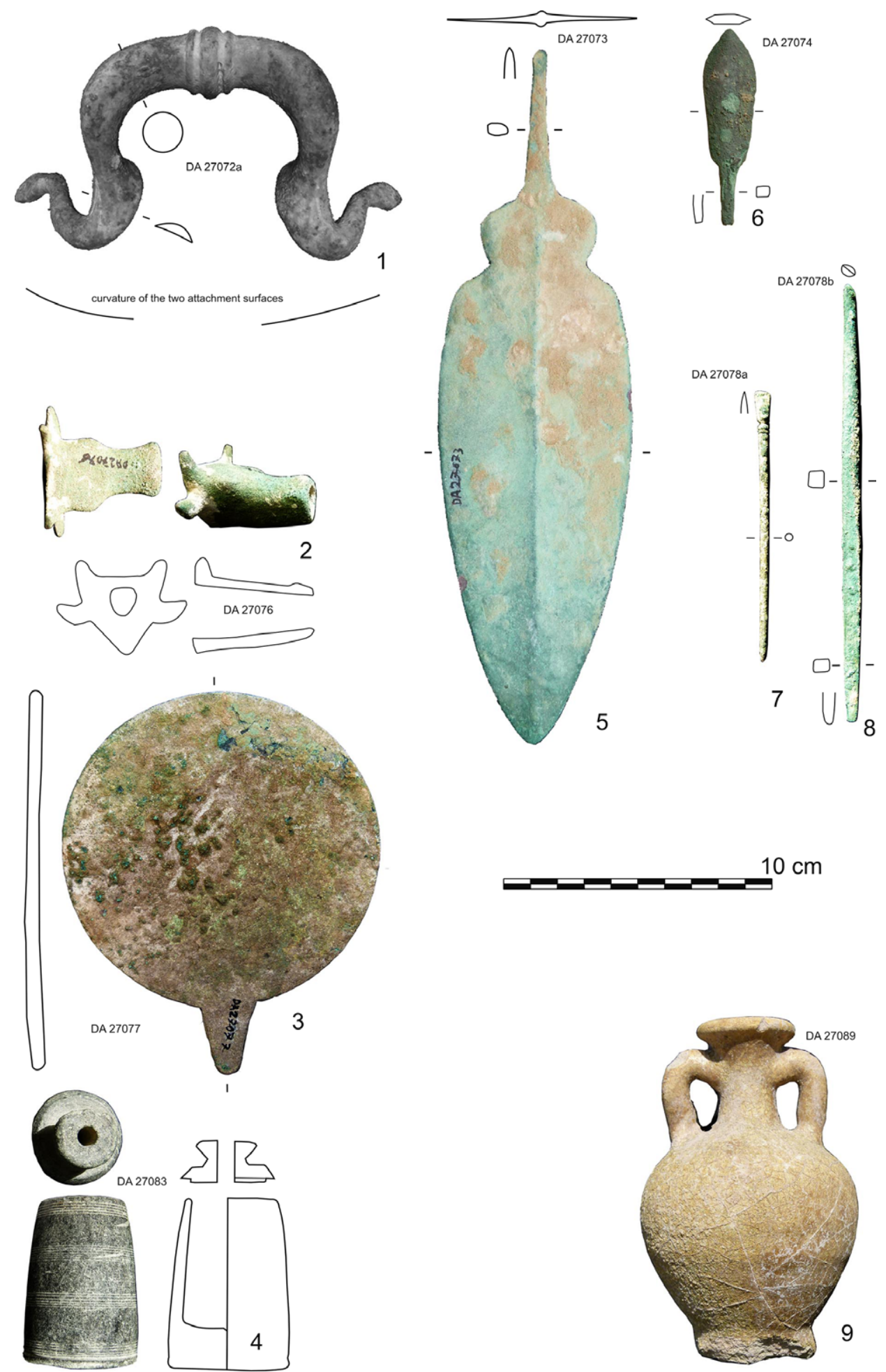

Fig. 4.

Artefacts lodged in the ministry, said to be from al-Juba (see Table 2) (photo: P. Yule). 


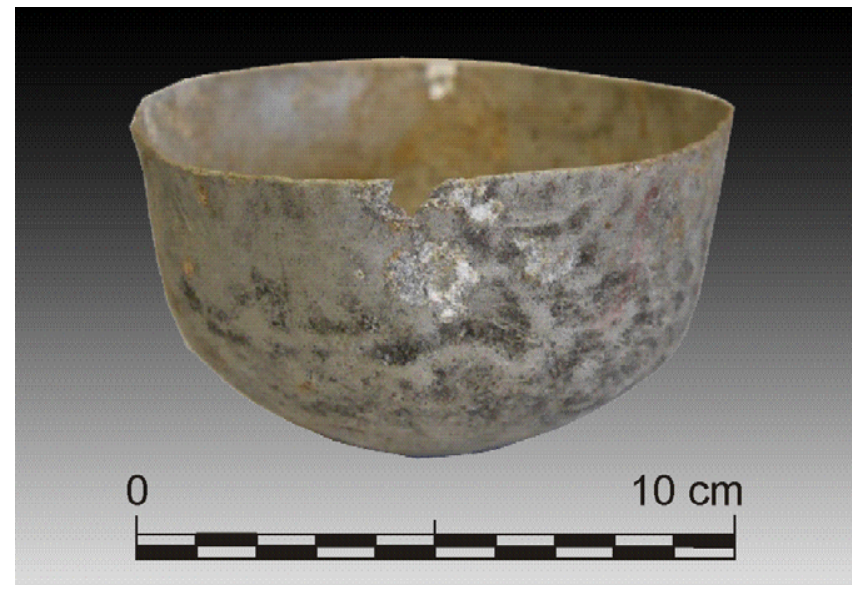

Fig. 5.

A silver bowl, DA 27070, chemically cleaned prior to acquisition (photo: C. Pariselle).

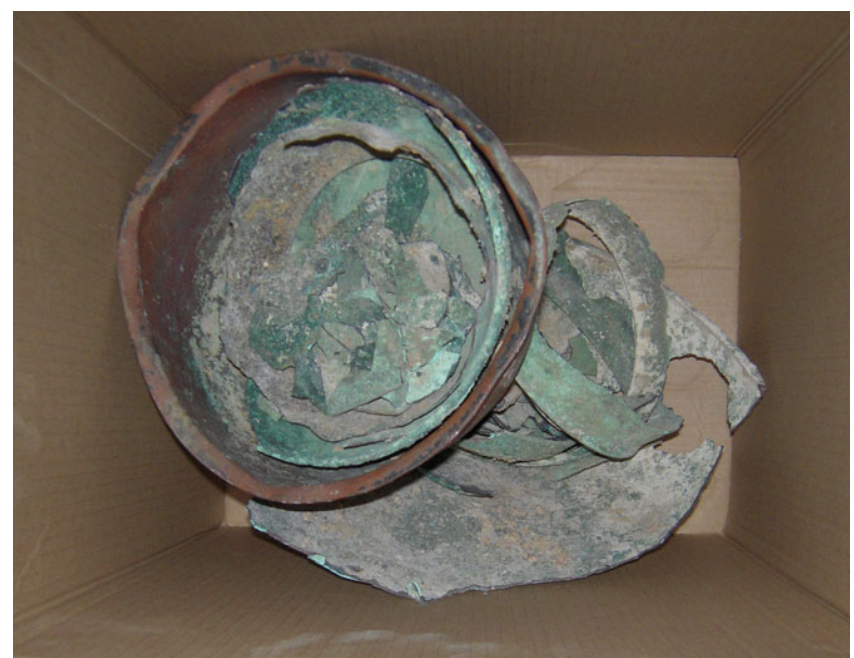

Fig 6.

Metal vessels said to be from al-Juba and handed in to the ministry (photo: P. Yule).

mirrored image differs from the drawing (Fig. 14). Close study of the radiograph reveals details that are not visible even in close-up photographs. For example, the artist endowed the dog-headed lions (fields $2 \& 6$ ) with chased shaggy manes and the snake-holding figures with female breasts (fields $4 \& 8$ ).

While the scribing appears at first to have been made with double lines (cf. Figs. 12 and 13) as noted above, in actual fact the corrosion has swelled on both sharp ridge edges of a given scribed line, lending it an odd appearance. The X-ray image shows the scribing to consist of well-controlled zigzag cuts made on the inside with a

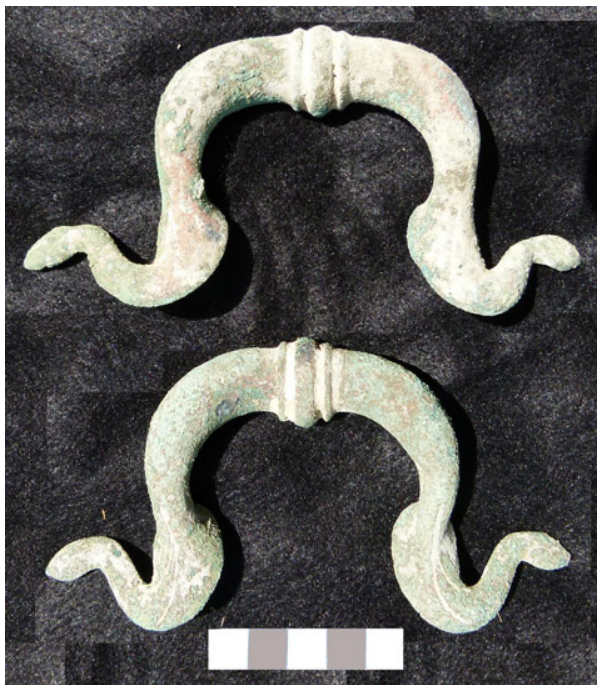

Fig 7.

Two copper alloy handles said to derive from al-Juba (photo: P. Yule).
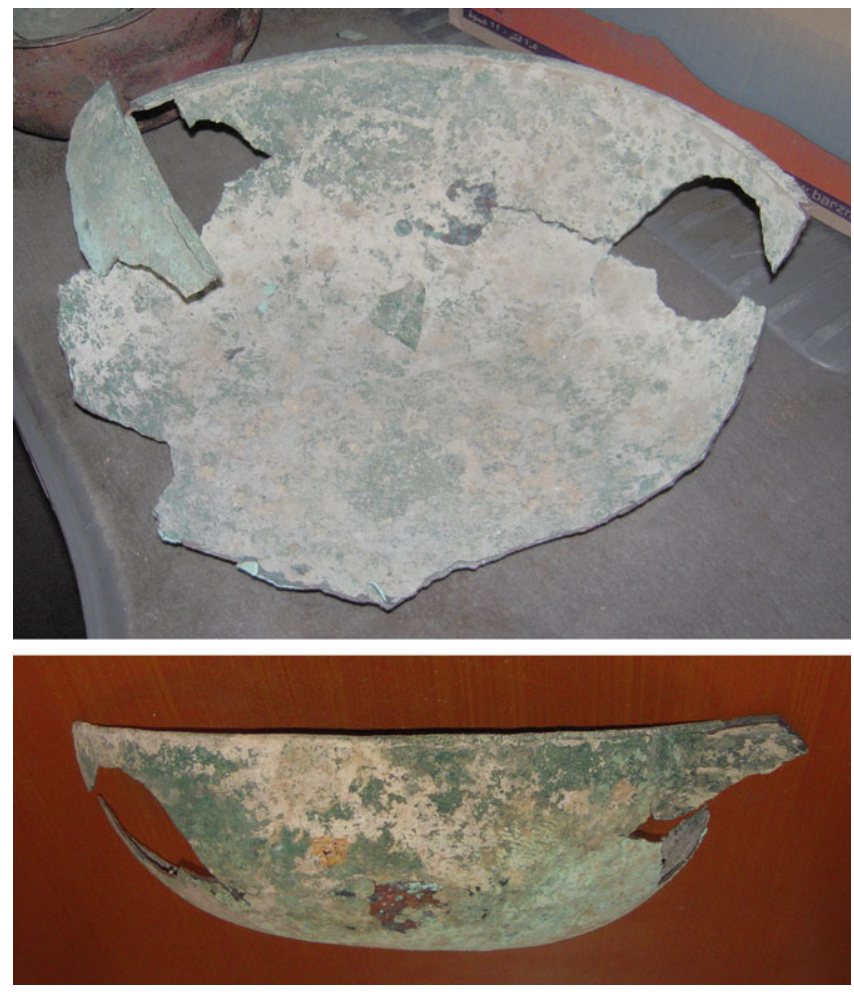

Fig 8 .

A copper alloy basin said to derive from al-Juba (photo: P. Yule).

burin. Metal was scribed but rarely removed. The scribing technique resembles most closely that of the hunting phiale from Samā'il (Yule, 2016: fig. 6.3) for which excellent photographs exist. The idea that this phiale is a 
(a)
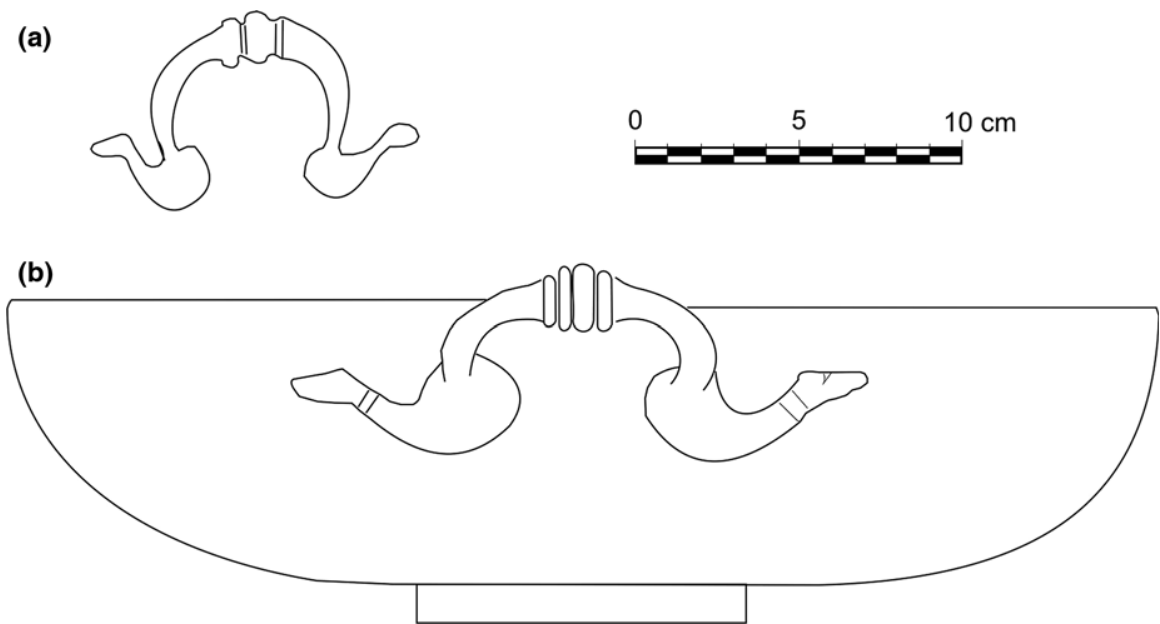

Fig. 9.

A copper basin handle and a 'Fußbecken' from two rich early imperial Roman graves in (a) Dollerupgaard and (b) Nörre = Broby, Denmark (after Eggers, 1949-50: 110 table. II). Many parallels are known from this part of Europe.

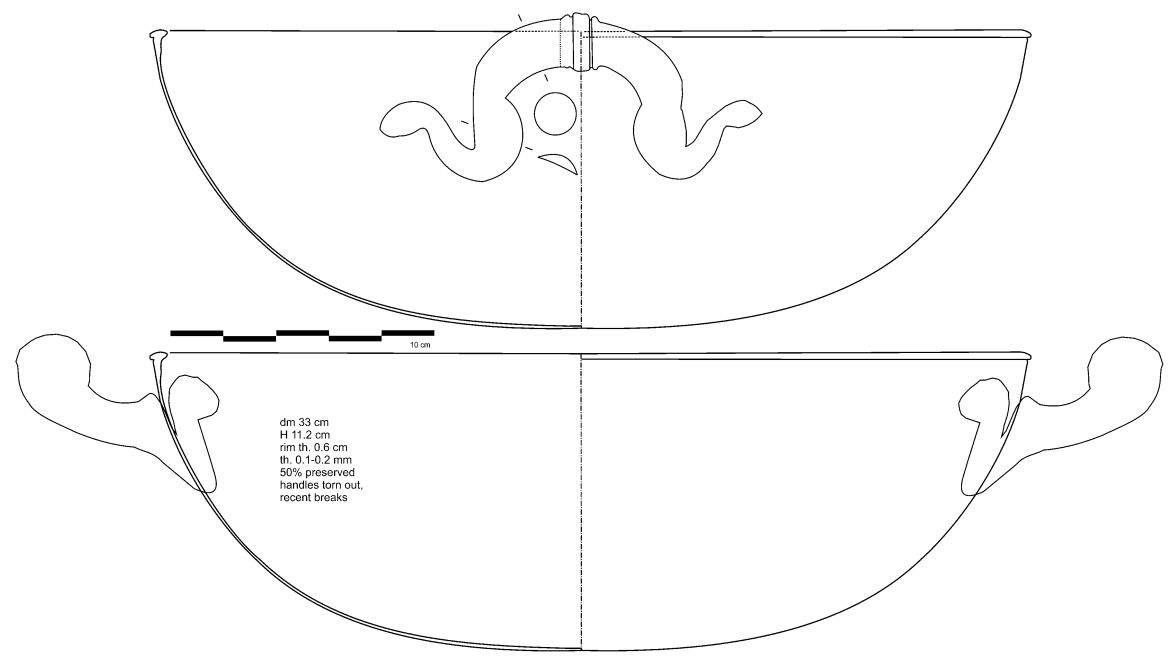

Fig. 10.

A reconstruction drawing of the two handles and basin in Figures 7 and 8 (drawing: P. Yule).

genetic precursor of Sasanian metal bowls cannot be substantiated.

The decoration engraved in the inside of the 'al-Juba' phiale (Figs. 12-14) shows archaic motifs familiar to students of Near Eastern archaeology, but less so to those of Arabia. Unfortunately, an entire artefactual categoryParthian decorated metal bowls - has not survived, which otherwise would help us contextualise the origin of the 'al-Juba' phiale and its kin.

The closest isolated excavated parallels derive from a PIR cemetery at 'Amlā'/al-Fuwaydah. Disappointingly, these bronze bowls have attracted little serious discussion, for one reason because typological parallels are few and difficult. One of these copper alloy phiales shows motifs ordered inside in concentric registers (Yule, 2016: fig. 6.1). Initially Yule designated such bowls as post-Phoenician (2001b: 280-281 with sources) to distinguish them from vaguely similar sixth-century BCE decorated bowls from the eastern Mediterranean. There is no clear way to establish influence, especially in light of the chronological difference between the two groups. A second phiale excavated from al-Fuwaydah shows a frieze of animals on the exterior just below the rim (Yule, 2016: fig. 6.2). Both are open bowls of the MeOB12 shape class, as is also that under discussion. The particular shape of thickening of the vessel lips of these late, different bowls is heterogeneous. Three differ from the rest in that they have a slightly raised omphalos (e.g. Yule, 2016: figs. $6.1 \& 6.3$ ). Moreover, the 


\section{P.A. YULE AND C. PARISELLE}

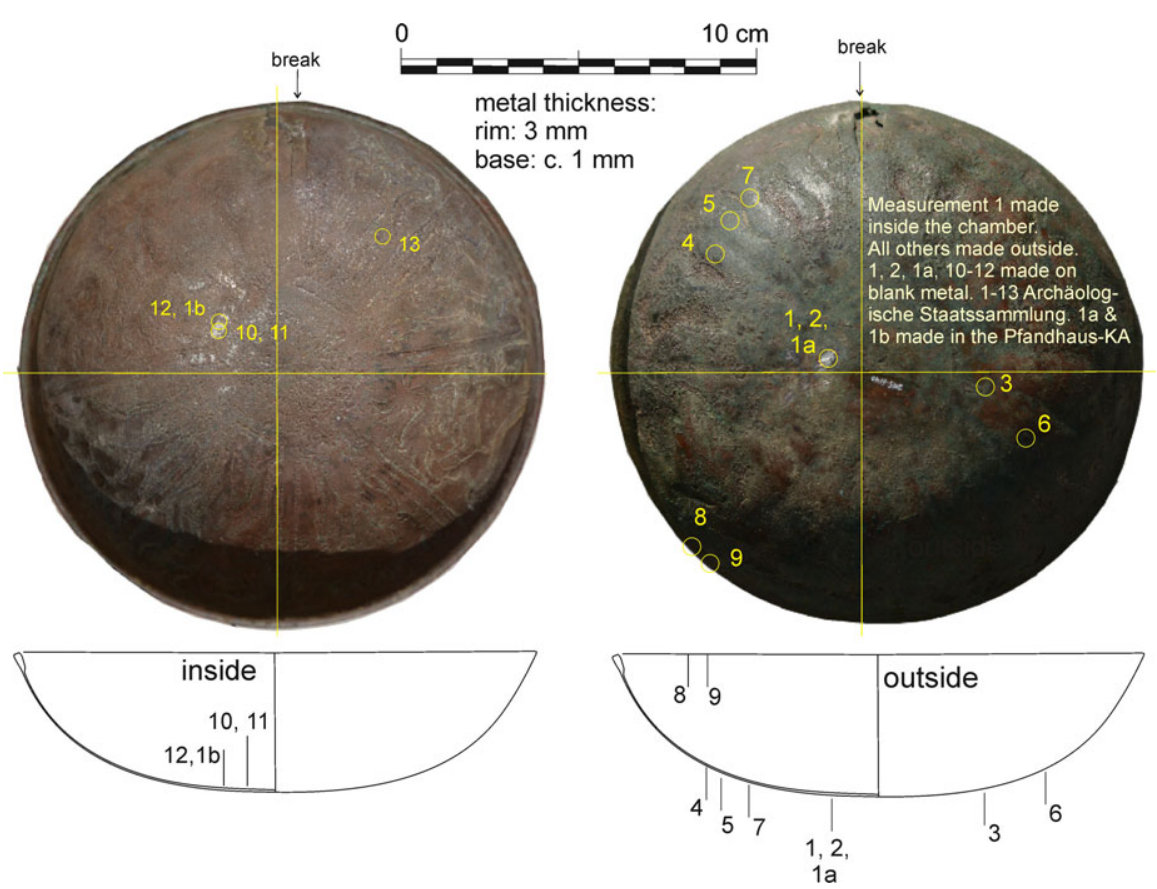

Fig. 11 .

Sampling areas where XRF readings were taken.

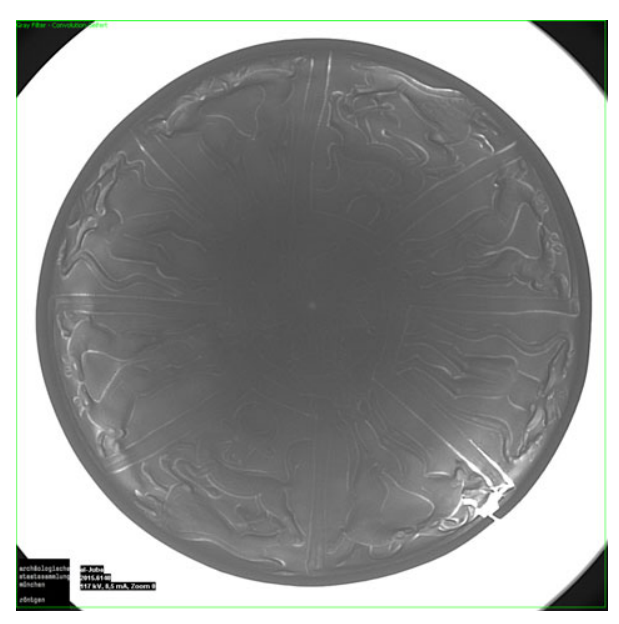

Fig. 12.

An X-ray of the outside of phiale 2015.6140, after 'soft' cleaning (photo: Bavarian State Archaeological Collection, Munich).

decoration of these phiales shows more differences than similarities in style, iconographic type and compositional syntax. There is a tendency towards concentric ring composition in different variants. The word 'style', as commonly used in art history, is of little use here; the figural and scribing styles are too heterogeneous to enable the study of fine differences among similar images. That most show a floral motif in the centre is clear, but this does not

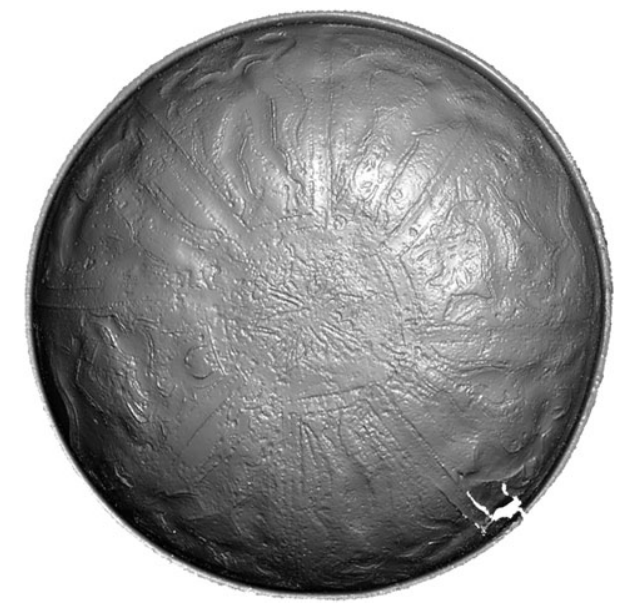

Fig. 13.

A 3D scan of phiale 2015.6140 taken with a Breuckmann Smart scan 3D scanner after 'soft' cleaning. The scan shows more contrast than is possible with conventional photography (photo: N. Abdali).

help to link them to each other. In the case of these decorated phiales, we cannot speak of one style but rather of motif groupings.

Our decorated phiale is interesting as a rare example of figural art in the Gulf region from the turn of the ages to the Common Era. The decoration brings to mind more Iranian interacted animal depictions than Mesopotamian 


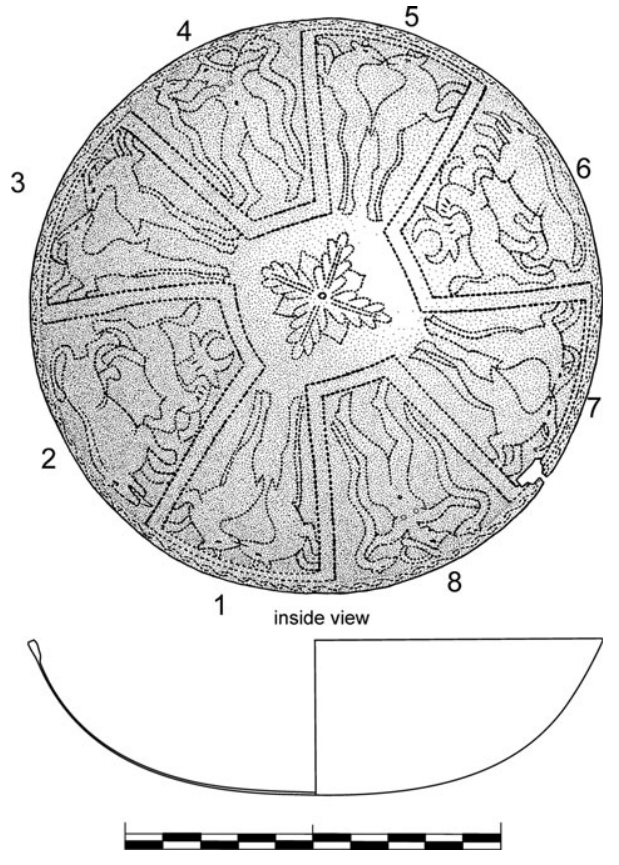

Fig. 14.

A rectified drawing of the inside of 2015.6140 (drawing: I. Blome).

Table 4. XRF phase measurements of the surface of phiale 2015.6140.

\begin{tabular}{|llrlll|}
\hline No. & $\% \mathrm{Ag}$ & $\% \mathrm{Cu}$ & $\% \mathrm{~Pb}$ & $\% \mathrm{Au}$ & out $/$ inside \\
\hline $\mathbf{1}$ & 89.23 & 9.13 & 0.64 & 0.42 & outside \\
$\mathbf{2}$ & 87.36 & 10.99 & 0.72 & 0.49 & outside \\
$\mathbf{3}$ & 44.36 & 54.60 & 0.64 & 0.15 & outside \\
$\mathbf{4}$ & 55.95 & 42.50 & 0.86 & 0.24 & outside \\
$\mathbf{5}$ & 76.26 & 20.99 & 0.44 & $<$ LOD & outside \\
$\mathbf{6}$ & 52.84 & 45.07 & 0.37 & $<$ LOD & outside \\
$\mathbf{7}$ & 70.99 & 27.43 & 0.60 & 0.26 & outside \\
$\mathbf{8}$ & 48.27 & 50.33 & 0.59 & 0.12 & outside \\
$\mathbf{9}$ & 49.86 & 48.45 & 0.49 & 0.04 & outside \\
$\mathbf{1 0}$ & 55.76 & 42.94 & 0.57 & 0.18 & inside \\
$\mathbf{1 1}$ & 59.12 & 39.69 & 0.65 & 0.28 & inside \\
$\mathbf{1 2}$ & 72.84 & 25.86 & 0.53 & 0.38 & inside \\
$\mathbf{1 3}$ & 77.22 & 20.34 & 0.76 & 0.17 & outside \\
\hline
\end{tabular}

hieratic ones. The rampant addorsed quadrupeds in fields $1,3,5$ and 7 , however, find few really close comparisons from neighbouring regions: many animal pairs are posed addorsed, as in the case of Mitanni common seals and sealings and Gulf seals, but rarely are they rampant. The so-called master of the animals or Gilgamesh motif is known over the millennia from many different variants, beginning with the decorated handle of the famous pre-dynastic Egyptian Jebel al-Araq knife and proto-Elamite seal designs (Frankfort, 1970: 34, fig. 25c). Variants appear on Gulf stamp seals, which show a central figure holding two animals at the throat (Kjaerum, 1983: 92-93 nos. 212-216). A central figure between two serpents also appears, but it is not grasping them (1983: 31 no. 54).

The closest comparable motif derives from the 'Intercultural Style', such as the soft-stone beaker held in the British Museum, said to be from Khafaji in Iraq (Strommenger \& Hirmer, 1964: pl. 38; Frankfort, 1970: 41, fig. 33). Casual perusal of the Internet under the keyword 'Jiroft' reveals several iconographically related parallels for a female or male figure grasping flanking serpents (cf. Anon., 2004 II: 781, cat. no. 491, excavated from Shahdad). Animal combat scenes also occur in the art of the Achaemenids and of other periods, but are unlike those of our phiale (Boardman, 2003: 135, Abb. 3, 34-35a-b). If there is only a dealer provenance, the originality lingers in some cases as a festering open question for decades, given the rarity of closely significant comparanda. Recently several authors have written about snake cults in south-east Arabia (e.g. Benoist, Pillault \& Skorupka 2011).

Open bowls came to light in Belgian excavations from Iron Age III graves in Luristan, in the Zagros, which may shed light on the origin of this kind of artefact. Although no exact iconographic matches exist, some compositions and vessel shapes are rather similar to those of MeOB12 bowls. One is decorated with a hunt and excavated from Chamahzi Mumah but has an omphalos (Haerinck \& Overlaet, 1998: 26, ill. 11.1.4). The similarity lies in the concentric register composition inside the bowl. A second vessel from there has a heavy, possibly cast, wall (1998: 26, ill. 11.1.1). Its ledged rim and shape closely match a bronze phiale from the PIR al-Fuwaydah grave Fu11 (Yule, 2016: fig. 6.1). A third undecorated example excavated from an Iranian Iron III grave at War Kabud in Luristan is a close match for the MeOB12 shape (Haerinck \& Overlaet, 2004: 59 fig. 20.6). It would be naive to date the phiale from grave Fu11 to the Iranian Iron III phase but these comparisons suggest what the ancestors of our phiale might have looked like. The decoration of the other MeOB12 phiales differs in various ways from the composition and figural style of ours. In light of its great early art industry, it is possible that these metal bowls were all produced in Iran. Suffice to say that this shape enjoyed wide popularity since the later first millennium BCE.

The phiale under discussion (Figs. 11-14) belongs to a shape class that has been taken to be diagnostic of the PIR (Yule, 2016), known largely from sites in today's UAE. If we lend credence to the dealer's 'al-Juba' provenance, then this MeOB12 phiale would have occurred in a Samad LIA grave, a find situation not observed until now. Either such bowls are not limited to the PIR or, exceptionally, 


\section{P.A. YULE AND C. PARISELLE}

one was traded as the first known example found coincidentally in a Samad LIA context.

We deeply regret that we did not have the luck to excavate the phiale ourselves. In that case much of the foregoing would have been superfluous. Although we cannot prove its originality beyond all possible doubt, on the strength of existing evidence, we hold it to be a unique original.

\section{Addendum}

After our manuscript went for publication we came upon a further example of Roman bronze handles for basins such as shown in Figure 10, but in the Yemen: D 'Aq11 \& Antonini, 2007: 225 cat. no. III.B.8 (Wādì Dura', Hajar amDhaybiyya, tomb 3, length: $14.5 \mathrm{~cm}$, date: first-second century $\mathrm{CE}=$ Breton \& Bāfaqīh, 1993: 27 no. 21, pl. 13, fig. 32 right.

\section{Acknowledgements}

We thank the Ministry of Heritage and Culture for their sustained support over the years and for permission to publish the artefacts cited below. Thanks also go to Jamal al-Moossawi, director of the National Museum, who took great pains to support and enable research in his institution. Christine Pariselle made the initial recording with Paul Yule. The conservation comments are hers. We are most grateful for the generous help from the Prähistorische Staatssammlung in Munich, especially from Rupert Gebhard and Barbara Jändl. Shimon Mahnke carried out the material analyses and made numerous X-ray images. The Interdisciplinary Center for Scientific Computing and Graduiertenkolleg of Heidelberg University financed the training of Negar Abdali (who conducted the 3D scanning), provided a scanner and financed a recording campaign in the new National Museum in Muscat. Finally, Reinhard Stupperich is thanked for his advice regarding Roman metal ware and for the H.J. Eggers citation. Stephan Merkel drew our attention to the literature on silver enrichment of the surface of archaeological artefacts. Armin Kirfel added useful criticism regarding the material analysis. Bruno Overlaet and the anonymous referees provided numerous citations and discussion, which up to now have been lacking. The authors could have expanded the discussion to include third- and second-millennium Iranian comparanda, which however, chronologically exceed their brief.

\author{
Abbreviations \\ EIA Early Iron Age \\ LBA Late Bronze Age \\ LIA Late Iron Age \\ PIR Période Préislamique Récente \\ WS Wadi Suq
}

The abbreviation MeOB12 stands for 'metal vessel open bowl class 12'. The find classes originated in Yule 2001a I and are partly revised in Yule \& Weisgerber 2015. DA nos. refer to the inventory of the Department of Antiquities.

\section{References}

'Aq11, A. \& Antonini, S. (2007). Bronzi sudarabici di periodo pre-islamico. (Repertorio iconografico sudarbico 3). Rome/Paris: De Boccard.

Anon. (2004). Katalog. In T. Stöllner, R. Slotta, \& A. Vatandoust (Eds.), Persiens antike Pracht. Bochum: Deutsches Bergbau-Museum: 694-699.

Beck, L., Bosonet, S., Réveillon, S., Elliot, D., $\&$ Pilon, F. (2004). Silver surface enrichment of silver-copper alloys: a limitation for the analysis of ancient silver coins by surface techniques. Nuclear Instruments and Methods in Physics Research Section B Beam Interactions with Materials and Atoms, 226: 153-162. doi:10.1016/j.nimb.2004.06.044
Benoist, A., Pillault, S., \& Skorupka, M. (2011). Rituels associés au symbole du serpent en Arabie orientale au cours de l'âge du Fer (1200-300 avant J.-C.): L'exemple de Bithnah (émirat de Fujairah). In Chr.J. Robin, \& I. Sachet (ed.), Dieux et déesses d'Arabie. Images et représentations, Actes de la table ronde tenue au Collège de France (Paris) les ler et 2 octobre 2007. Paris: De Boccard: 211-259.

Boardman, J. (2003). Die Perser und der Westen. Mainz: Otto von Zabern.

Breton, J.-F. \& Bāfaqīh, M. (1993). Trésors du Wādī Dura' (République du Yémen). (Inst. Français d'archéologie du Proche-Orient, Bibliothèque archéologique et historique, t. 141). Paris: Geuthner.
De Puma, R.D. (1991). The Roman bronzes from Kolhapur. In V. Begley, \& R. De Puma (Eds.), Rome and India, the ancient sea trade. Madison: University of Wisconsin Press: 82-112.

Eggers, H.J. (1949-50). Lübsow, ein germanisches Fürstengrab der älteren römischen Kaiserzeit. Prähistorische Zeitschrift, 34-35(2): 58-111.

Frankfort, H. (1970). The art and architecture of the ancient Orient. Harmondsworth: Penguin.

Haerinck, E. (2001). The tombs, excavations at ed-Dur (Umm al-Qaiwain, United Arab Emirates), vol. 2. Leuven: Peeters.

Haerinck, E., \& Overlaet, B. (1998). Chamahzi Mumah, an Iron Age III 


\section{SILVER PHIALE FROM OMAN}

graveyard. (Luristan Excavation Documents 2). Leuven: Peeters.

Haerinck, E., \& Overlaet, B. (1999). Djub-i Gauhar and Gul Khanan Murdah, Iron Age III graveyards in the Aivan Plain. (Luristan Excavation Documents 3). Leuven: Peeters.

Haerinck, E., \& Overlaet, B. (2004). The Iron Age III graveyard at War Kabud, Pusht-i Kuh, Luristan. (Luristan Excavation Documents 5). Leuven: Peeters.

Hakemi, A. (1997). Shahdad archaeological excavations of a Bronze Age center in Iran. (Reports and Memoirs 27). Rome: IsIAO.

Jasim, S.A. (2012). The necropolis of Jebel al-Buhais, prehistoric discoveries in the Emirate of Sharjah, United Arab Emirates. Sharjah: Department of Culture \& Information.

Kjaerum, P. (1983). Failaka/Dilmun: The second millennium settlements. Vol. 1/1: The stamp and cylinder seals. Moesgård: Jutland Archaeological Society Publications.

Rose, J., Hilbert, Y., Charpentier, V., \& Crassard, R. (2012). Survey of prehistoric archaeological sites in the Fasad region, southern Rub'A1 Khali, Sultanate of Oman Archaeological Survey Report 29th-30th
January 2012. Unpublished report for the Ministry of Heritage and Culture Sultanate of Oman.

Strommenger, E., \& Hirmer, M. (1964). 5000 years of the art of Mesopotamia. New York: Abrams.

Vogt, B. (1994). Asimah - an account of a two months rescue excavation in the mountains of Ras al-Khaimah. Ras al-Khaimah: Department of Antiquities and Museums.

Yule, P. (2001a). Die Gräberfelder in Samad al-Shan (Sultanat Oman), Materialien zu einer Kulturgeschichte. (Deutsches Archäologisches Institut, OrientAbteilung, Orient-Archäologie 4). Rahden: Leidorf. Text retrieved from http:// digi.ub.uni-heidelberg.de/diglit/ yule2001 textplates retrieved from http:// diglit.ub.uni-heidelberg.de/diglit/ yule2001ga

Yule, P. (2001b). Recently discovered bronze bowls from 'Amlah, al-Zahirah Province and the late pre-Islamic culture of Oman. BaM, 32: 255-287. Retrieved from http:// archiv.ub.uni-heidelberg.de/ propylaeumdok/volltexte/2009/183/

Yule, P. (2002). GIS covering the past in Oman, Geo-Information-System. GeoConnexion, 1: 48-49. Retrieved from https://uni-heidelberg.academia.edu/ paulyule and http://archiv.ub.uniheidelberg.de/propylaeumdok/volltexte/ 2015/2483

Yule, P. (2014a). A New Prehistoric Anthropomorphic Figure from the Sharqiyah, Oman. In C.C. LambergKarlovsky, B. Genito, \& B. Cerasetti (Eds.), 'My Life is like the Summer Rose', Maurizio Tosi e l'Archaeologia come modo di vivere, Papers in Honour of Maurizio Tosi for his 70th Birthday. (British Archaeological Reports, British Series 2690). Oxford: BAR Publishing: 759-760.

Yule, P. (2014b). Cross-roads - Early and Late Iron Age south-eastern Arabia. (Abhandlungen Deutsche OrientGesellschaft 30). Wiesbaden: Harrassowitz.

Yule, P. (2016). Valorising the Samad Late Iron Age. Arabian Archaeology and Epigraphy, 27: 31-71.

Yule, P., \& Weisgerber, G. (2015). Al-Wāsit Tomb W1 and other sites. Materials for a definition of the second half of the 2nd millennium BCE. In P. Yule (Ed.), Archaeological Research in the Sultanate of Oman. (Der Anschnitt Beiheft 28). Bochum: Verlag Marie Leidorf: 9-108. 